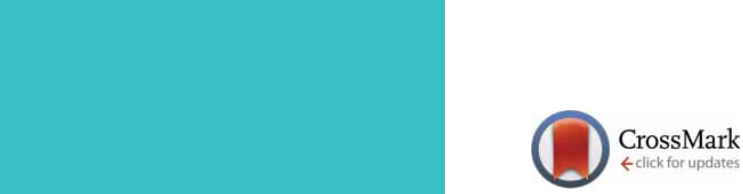

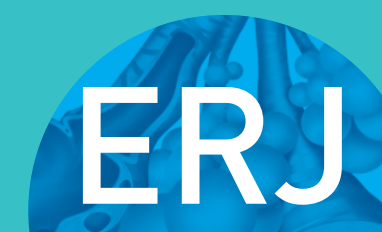

open research
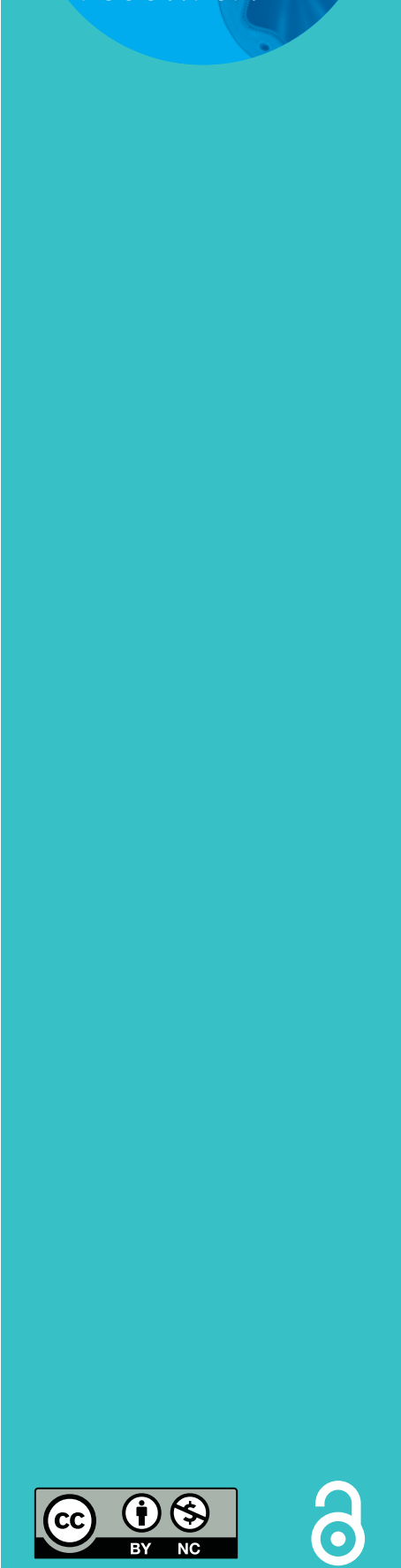

\section{Research priorities for respiratory nursing: a UK-wide Delphi study}

\author{
Carol Ann Kelly (1) 1 , Andrew J. Kirkcaldy (1) ${ }^{2}$, Melissa Pilkington², \\ Matthew Hodson ${ }^{3}$, Lindsay Welch ${ }^{4}$, Janelle Yorke ${ }^{5}$ and Katherine Knighting (1) ${ }^{2}$
}

Affiliations: ${ }^{1}$ Postgraduate Medical Institute, Edge Hill University, Ormskirk, UK. ${ }^{2}$ Evidence-based Practice Research Centre, Edge Hill University, Ormskirk, UK. ${ }^{3}$ Homerton University Hospital Foundation Trust and Association of Respiratory Nurse Specialists, London, UK. "Solent NHS Trust and the University of Southampton, and Association of Respiratory Nurse Specialists, Southampton, UK. ${ }^{5}$ Division of Nursing, Midwifery and Social Work, Faculty of Biology, Medicine, Health Sciences, University of Manchester, Manchester, UK.

Correspondence: Carol Ann Kelly, Applied Health and Social Care, Faculty of Health and Social Care, Edge Hill University, St Helens Road, Ormskirk, L39 4QP, UK. E-mail: kellycdedgehill.ac.uk

ABSTRACT Respiratory nurses make a significant contribution to the delivery of respiratory healthcare, but there is a dearth of nurse-led, practice-focused, published research.

Using a modified three-round Delphi, this study sought to identify research priorities for respiratory nursing to inform a national research strategy. Study information and the survey link were sent electronically to members of UK professional respiratory organisations. Round 1 had 78 items across 16 topics, informed by a systematic literature review. Respondents suggested additional items which were content analysed to inform Round 2. Respondents rated all items and ranked the topics in all rounds. To ensure rigour, rounds had an explicit focus with pre-determined criteria for consensus (70\%).

In total, 363 responses were received across Rounds 1,2 and 3 ( $\mathrm{n}=183,95$ and 85, respectively). The top five research priorities were: 1) "Patient understanding of asthma control"; 2) "The clinical and cost-effectiveness of respiratory nurse interventions"; 3) "The impact of nurse-led clinics on patient care"; 4) "Inhaler technique"; and 5) two topics jointly scored: "Prevention of exacerbations" and "Symptom management".

With potential international significance, this is the first UK study to identify research priorities for respiratory nursing, providing direction for those planning or undertaking research.

@ERSpublications

UK-wide Delphi survey identifies nursing research priorities to enhance respiratory care for patients and carers http://ow.ly/ekGt30iXYXt

Cite this article as: Kelly CA, Kirkcaldy AJ, Pilkington M, et al. Research priorities for respiratory nursing: a UK-wide Delphi study. ERJ Open Res 2018; 4: 00003-2018 [https://doi.org/10.1183/ 23120541.00003-2018].

Received: Jan 062018 | Accepted after revision: March 092018

Copyright $\odot$ ERS 2018. This article is open access and distributed under the terms of the Creative Commons Attribution Non-Commercial Licence 4.0. 


\section{Introduction}

Respiratory disease imposes a considerable impact on patients in terms of mortality and morbidity, and upon their families and carers [1]. Additionally, there is a significant impact on healthcare utilisation and economic cost both nationally and internationally [2,3]. In Europe, $12 \%$ of all deaths are attributed to respiratory disease with over 6 million hospital admissions per annum recorded [3]. In the UK, around 12 million people are diagnosed with lung disease with considerable impact on quality of life, with many patients experiencing a gradual disease progression and subsequent consequences to day-to-day physical functioning, and emotional and psychosocial wellbeing $[1,3]$.

It is recognised that respiratory nurses, as key members of the respiratory multidisciplinary team, make an important contribution to the care and management of respiratory patients and the delivery of respiratory healthcare services $[4,5]$. However, there is limited published evidence regarding the role of respiratory nurses, and a paucity of research into the cost-effectiveness and clinical value of nurse-led care and services $[5,6]$.

In times of economic austerity there is a global need to focus on models of caring for long-term respiratory patients. In the UK, strategic policy from the Dept of Health sets out a new shared vision for the future of the National Health Service [7]. The focus is on lifestyle choices, chronic conditions and ageing. With an emphasis on integrated models of care, the strategy highlights areas that nurses play a key role in, including public health messages, self-care and service configuration. Many respiratory patients have existing comorbidities and complex needs, yet research regarding both the interventions and the impact of respiratory nursing care is underdeveloped [6]. The current clinical situation often does not facilitate nurses participating in, or undertaking, high-quality research [8]. There is a need not only to develop services but also to measure the impact of interventions to meet the changing needs of an ageing population and the subsequent increasing number of individuals living with long-term respiratory conditions. Respiratory nurses are ideally placed to lead and facilitate high-quality, collaborative, multidisciplinary research that is relevant to people living with a respiratory condition, their lay carers, families, and health and social care provision. With limited resources, however, identifying and outlining relevant research priorities may facilitate a focus on current gaps to progress research in this area.

The American Thoracic Society has previously set out research priorities in respiratory nursing $[9,10]$. Key priorities were identified, including health promotion, disease prevention and end-of-life care, which informed the survey of this current study. Additionally, disease-specific research priorities have been identified by nurses such as lung cancer nurse specialists [11], and cystic fibrosis research priorities compiled by the Allied Health and Nursing Professions Working Group [12] and through research collaborations such as EMBARC (European Multicentre Bronchiectasis Audit and Research Collaboration) [13].

Other research priority studies included a published editorial outlining a review of UK respiratory research priorities in 2008 [14], and an e-Delphi survey of 23 experts from 21 countries in order to identify and prioritise the respiratory research needs of primary care conducted by the International Primary Care Respiratory Group [15]. However, these studies had very little or no nursing representation and do not have a nursing focus.

It is apparent that there is potential for respiratory nurses to lead research related to the multidisciplinary care and management of respiratory patients and the provision of respiratory services. However, as there are no current UK national respiratory nurse research priorities, a Delphi survey was undertaken to establish a consensus.

\section{Materials and methods}

A three-round modified Delphi technique utilising an online survey (SurveyMonkey; www.surveymonkey. com) was conducted with respiratory nurses from UK professional organisations to identify research priorities for respiratory nursing. The data was collected from July 2016 to November 2016. The Delphi technique was chosen as it is a recognised method for identifying and prioritising views on a variety of topics. The method has been successful in identifying national priorities in health research $[16,17]$ and has a strong track record in nursing $[18,19]$. The methods and sample sizes for the study are illustrated in figure 1. The CREDES (Guidance on Conducting and REporting DElphi Studies) guidelines were utilised to present the study [20].

There is no agreed level of consensus for Delphi studies as it is dependent upon the sample numbers and the aim of the research [21-24]. However, it is vital for rigour and transparency that each study has an agreed upon criterion [24-26]. To ensure rigour, each round of the Delphi in this study had an explicit focus, with the following pre-determined criteria for consensus and any changes made to items between rounds: 1) "criterion to accept an item": at least $70 \%$ of the respondents rated an item as "important" 


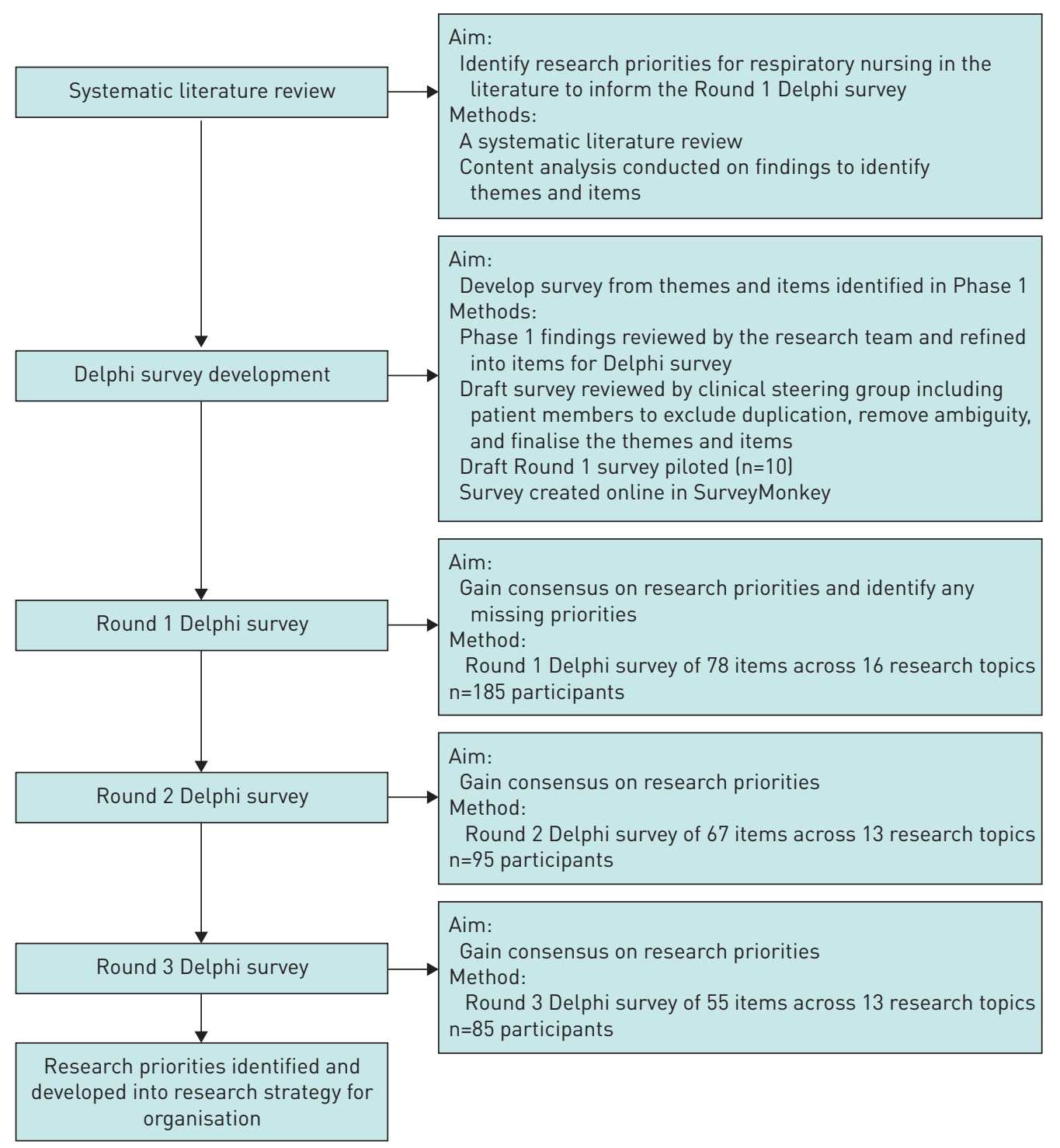

FIGURE 1 Flowchart of multiphase modified Delphi phases.

(score of 4 points) or "extremely important" (score of 5 points); and 2) "criterion for rejecting an item": any items that did not meet the $70 \%$ criteria and rating median of $\geqslant 4$ points.

Ethical approval for the project was granted by the Faculty Research Ethics Committee, Edge Hill University (FOH116).

\section{Recruitment}

The study used a purposive, organisational approach to recruitment, rather than a small expert panel, to facilitate engagement of respiratory nurses from across the UK. The 1100 members of the Association of Respiratory Nurse Specialists (ARNS), along with respiratory nurses of the British Thoracic Society and the Primary Care Respiratory Society UK, were invited to participate in the online survey by e-mail via the ARNS secretariat and use of social media.

\section{Development of Round 1 Delphi survey}

A systematic literature review was undertaken in April 2016 using key terms to search MEDLINE and CINAHL online databases, conference proceedings, and government and key respiratory organisation websites to identify research recommendations for respiratory nursing. After applying the screening criteria, 65 peer-reviewed papers were included in the review, along with current international guidance 
documents and clinical guidelines. Details of the criteria and search are presented in figure 2, adapted from PRISMA [27].

Four overarching themes and subthemes (topics) of research recommendations were identified from the literature and used to inform Round 1 of the Delphi, which were related to specific diseases, care interventions or models of care delivery (table 1).

The draft survey was reviewed and piloted before being finalised for dissemination. The Round 1 Delphi survey had three sections that collected demographics, and asked participants to rate 78 items across 16 topics by "How important do you think it is to include the following items as priorities in the future nursing research strategy?" on a five-point Likert scale (1 being "not at all important" and 5 being "extremely important") and rank the topic areas, indicating which were the top five priority topics.

\section{Analysis}

All qualitative data gathered through the open responses, including any new items suggested by respondents in Round 1, were analysed using a content approach by C.A.K., verified by K.K., and then reviewed by the full team and clinical steering group before being added to the Round 2 survey [28]. The quantitative data were entered into SPSS Statistics for Windows version 22 (IBM, Armonk, NY, USA) for analysis. Summary statistics of measures of central tendency (mean, median) and level of dispersion (standard deviation, interquartile range) were computed to determine the spread of responses and the number of items that met the pre-determined criteria for consensus of $70 \%$ for each round [23]. A classical Delphi tends to remove items where there is consensus, retaining only those where consensus has not been reached for additional consideration in subsequent rounds. This approach has been modified in

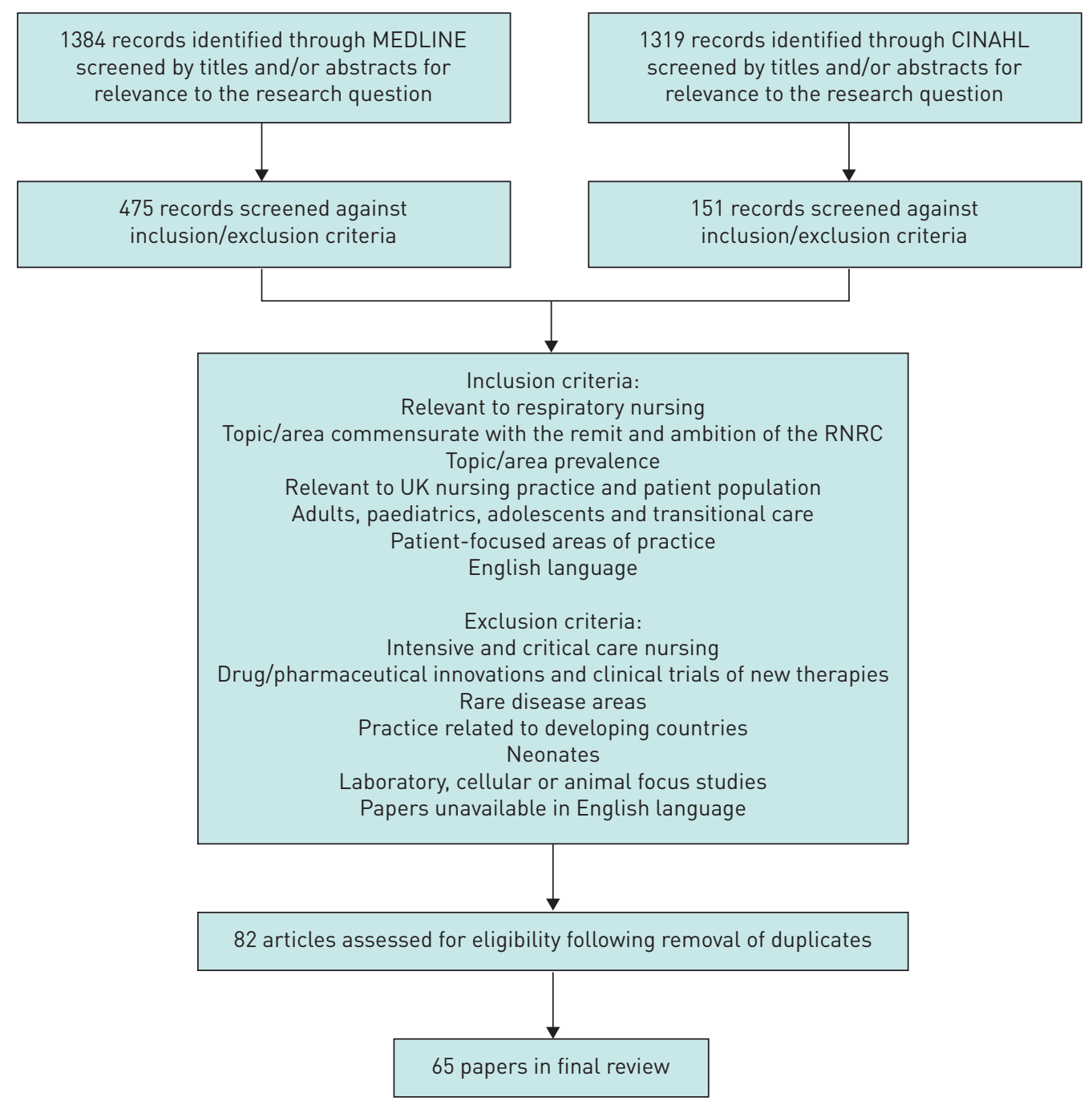

FIGURE 2 Flowchart of literature search. RNRC: Respiratory Nurse Research Consortium. 


\section{TABLE 1 Themes and subthemes (topics) identified from the literature review}

Theme

Theme 1: Prevention of respiratory disease and related disability

Theme 2: Disease management

Theme 3: Organisation and delivery of care

Theme 4: Palliative care

\section{Subthemes (topics)}

Smoking behaviour

Exercise for respiratory health

Prevention and early intervention

Self-management

Pulmonary rehabilitation

Cognitive behavioural therapy

Disease-specific topics for chronic obstructive pulmonary disease, asthma, bronchiectasis, cystic fibrosis, interstitial lung disease, lung cancer and obstructive sleep apnoea syndrome

Care pathways

Clinical and cost-effectiveness of respiratory nurse intervention

Role effectiveness (e.g. cost and quality outcomes for respiratory nursing care interventions)

Nurse prescribing in respiratory care limpact on disease management and cost; acceptability to patients)

Impact of nursing assessment, examination and intervention

Nurse-led clinics (advantages, disadvantages, outcomes)

Telehealth and telemedicine

Economics of care delivery

Primary care models of respiratory care

Expert patient/patient support groups

Education and training of nurses in respiratory care

Infection control

Models of care

Outcome measures

Adherence to guidelines

Decision making

Style/format of communication

Recognising the palliative care phase

Care for carers

Impact on carers

Skills/training

Symptom management

Models of end-of-life/palliative care delivery

Complimentary therapies

studies that have sought to refine and reduce the number of items to identify items or priorities [24-26]. In this modified Delphi where there was clear disagreement about the importance of an item according to the pre-set criteria, the item was removed. Items that met the consensus criteria were retained for another round of rating to provide further refinement of the ranking of priorities perceived as important for nurse-led respiratory research. Feedback of the group response for items from the previous round was provided in each new round. Mean scores were calculated for the final Round 3 and used to rank the remaining 55 items, across all items and within the remaining 13 topics.

\section{Results}

Participants

It is unknown how many individuals received and opened the e-mail invitation to participate for Round 1, so the full membership of ARNS was used to calculate an approximate response rate for Rounds 1, 2 and 3 at $17 \%, 9 \%$ and $8 \%$, respectively. Delphi studies often report response rates lowering as rounds increase with organisational studies, reporting 6-8\% average response rates [29]. The demographic spread of respondents was representative of the ARNS membership composition: respondents were from all areas of the UK; the majority were Respiratory Nurse Specialists, had worked in respiratory nursing for 11-20 years and worked in adult services (table 2).

\section{Delphi rounds}

The changes to the topics and items between rounds after the consensus criteria were applied are shown in table 3. Three topics and 26 items were removed, leaving 55 items across 13 topics in the final list of research priorities. 


\begin{tabular}{|c|c|c|c|}
\hline Demographics & Round 1 & Round 2 & Round 3 \\
\hline Subjects & 183 & 95 & 85 \\
\hline \multicolumn{4}{|l|}{ Current role/job title } \\
\hline Advanced Nurse Practitioner & $11(6)$ & $9(10)$ & $6(7)$ \\
\hline Asthma Nurse & $4(2)$ & $1(1)$ & $1(1)$ \\
\hline Consultant Nurse & $9(5)$ & $4(4)$ & $5(6)$ \\
\hline Paediatric Nurse & $3(2)$ & 0 & 0 \\
\hline Practice Nurse & $20(11)$ & $10(11)$ & $10(12)$ \\
\hline Research Nurse & $8(4)$ & $5(5)$ & $5(6)$ \\
\hline Respiratory Nurse & $15(8)$ & $11(12)$ & $8(10)$ \\
\hline Respiratory Nurse Specialist & $82(45)$ & $34(36)$ & $29(36)$ \\
\hline Team Lead Manager & $17(9)$ & $6(6)$ & $2(3)$ \\
\hline Other & $4(2)$ & 7 (7) & 15 (19) \\
\hline No response & $10(5)$ & $8(8)$ & $4(5)$ \\
\hline \multicolumn{4}{|c|}{ Length of time working in a respiratory specialism years } \\
\hline$<5$ & $17(9)$ & $12(13)$ & $9(11)$ \\
\hline $5-10$ & $44(24)$ & $22(23)$ & $24(30)$ \\
\hline $11-20$ & $82(45)$ & $34(36)$ & $28(35)$ \\
\hline$>20$ & $30(16)$ & $19(20)$ & $20(25)$ \\
\hline No response & $10(6)$ & $8[8]$ & $4(5)$ \\
\hline \multicolumn{4}{|c|}{ Type of service currently working in } \\
\hline Primary care & $48(26)$ & $34(36)$ & 27 (32) \\
\hline Community care & $37(20)$ & $20(21)$ & $20(24)$ \\
\hline Secondary care & $77(42)$ & $37(37)$ & $34(40)$ \\
\hline Tertiary care & $7(4)$ & $4(4)$ & $5(6)$ \\
\hline Intermediate care & $5(3)$ & $4(4)$ & $4(5)$ \\
\hline Other & $20(11)$ & $6(6)$ & $7(8)$ \\
\hline \multicolumn{4}{|c|}{ Type of patient group primarily working with } \\
\hline Paediatrics & $4(2)$ & $1(1)$ & $3(4)$ \\
\hline Adults & $137(75)$ & $70(74)$ & 59 (73) \\
\hline Both paediatrics and adults & $32(18)$ & $16(17)$ & $19(24)$ \\
\hline No response & $10(5)$ & $8(8)$ & $4(5)$ \\
\hline
\end{tabular}

\section{Consensus results}

The key research priorities identified by respondents after three rounds of the Delphi were identified. Given the breadth of work undertaken in the respiratory nursing specialism, it is not surprising that different research priorities were rated as relevant for different nurses and services, creating a spread across the themes. Table 4 reports the research priorities ranked by mean score. All items remaining achieved a high level of consensus.

Theme 2 ("Disease management") was the dominant theme, with a number of practice areas identified as priorities for future research, including some disease-specific areas, inhaler technique, and psychological management of anxiety and depression. Theme 3 ("Organisation and delivery of care") had the second most priorities, with priorities around establishing an evidence base of the impact of respiratory nursing and the quality and impact of training. Smoking behaviours of children and adults was the highest ranked item for Theme 1 ("Prevention of respiratory disease and related disability"), and an integrated approach to palliative care delivery for Theme 4 ("Palliative care").

\section{Discussion}

This article presents findings from the first UK-wide Delphi study to identify research priorities for respiratory nursing. e-Delphis conducted using online software have become very popular with the advancement of the internet [30]. The findings provide a basis for a UK respiratory nurse research strategy, direction for the European perspective and an update to the previously identified US respiratory nurse research priorities $[9,10]$.

The literature review identified a diverse range of research recommendations related to respiratory nursing that were organised into four main themes. The key research priorities, identified by means of consensus, reflect topical issues in respiratory care that are deemed important to respiratory nursing. 
TABLE 3 Distribution and changes to survey items and topics between rounds

\begin{tabular}{|c|c|c|c|c|c|c|}
\hline \multicolumn{2}{|c|}{ Topic } & \multirow{2}{*}{$\begin{array}{c}\text { Round } 1 \\
\text { n } \\
6\end{array}$} & \multirow{2}{*}{$\begin{array}{c}\text { Change to } \\
\text { Round } 2 \\
+1\end{array}$} & \multirow{2}{*}{$\begin{array}{c}\text { Round } 2 \\
\text { n } \\
7\end{array}$} & \multirow{2}{*}{$\begin{array}{c}\text { Change to } \\
\text { Round } 3 \\
-3\end{array}$} & \multirow{2}{*}{$\begin{array}{c}\text { Round } 3 \\
\text { n } \\
4\end{array}$} \\
\hline 1 & $\begin{array}{l}\text { Approaches to the prevention of respiratory } \\
\text { disease }\end{array}$ & & & & & \\
\hline 2 & $\begin{array}{l}\text { Self-management of chronic respiratory } \\
\text { disease }\end{array}$ & 7 & +1 & 8 & -1 & 7 \\
\hline 3 & Pulmonary rehabilitation & 8 & -3 & 5 & -2 & 3 \\
\hline 4 & Psychological interventions & 3 & 0 & 3 & 0 & 3 \\
\hline 5 & $\begin{array}{l}\text { Management of long-term respiratory } \\
\text { conditions }\end{array}$ & 10 & -4 & 6 & 0 & 6 \\
\hline 6 & Family and unpaid carers & 3 & -1 & 2 & 0 & 2 \\
\hline 7 & $\begin{array}{l}\text { Management of chronic obstructive } \\
\text { pulmonary disease }\end{array}$ & 4 & 0 & 4 & -1 & 3 \\
\hline 8 & Management of asthma & 6 & -1 & 5 & -1 & 4 \\
\hline 9 & Management of bronchiectasis & 3 & 0 & 3 & -2 & 1 \\
\hline 10 & Management of cystic fibrosis" & 3 & -3 & 0 & 0 & 0 \\
\hline 11 & Management of interstitial lung disease & 2 & +2 & 4 & 0 & 4 \\
\hline 12 & $\begin{array}{l}\text { Management of obstructive sleep apnoea } \\
\text { syndrome }\end{array}$ & 2 & -2 & 0 & 0 & 0 \\
\hline 13 & Organisation and delivery of care & 9 & -1 & 8 & -1 & 7 \\
\hline 14 & Education and training of nurses & 4 & +3 & 7 & -1 & 6 \\
\hline 15 & Telehealth and telemedicine ${ }^{\#}$ & 4 & -4 & 0 & 0 & 0 \\
\hline 16 & Palliative care & 4 & +1 & 5 & 0 & 5 \\
\hline Tot & & 78 & -11 & 67 & -12 & 55 \\
\hline
\end{tabular}

\#: Topics 10, 12 and 15 were removed based on analysis of Round 1 data, leaving 13 topics for Rounds 2 and 3.

\section{TABLE 4 Key research priorities ranked by mean score}

\begin{tabular}{|c|c|c|c|c|}
\hline Rank & Research priorities & $\begin{array}{l}\text { Theme } \\
\text { (topic) }{ }^{\#}\end{array}$ & $\begin{array}{c}\text { Consensus } \\
\%\end{array}$ & $\begin{array}{l}\text { Mean } \\
\text { score }\end{array}$ \\
\hline 1 & Patient understanding of asthma control" ${ }^{\text {ๆ }}$ & $2(8)$ & 91 & 4.47 \\
\hline 2 & $\begin{array}{l}\text { The clinical and cost-effectiveness of respiratory nurse } \\
\text { interventions }\end{array}$ & $3(13)$ & 90 & 4.45 \\
\hline 3 & The impact of nurse-led clinics on patient care & $3(13)$ & 92 & 4.41 \\
\hline 4 & Inhaler technique & $2(2)$ & 83 & 4.40 \\
\hline $5=$ & Prevention of exacerbations ${ }^{\natural}$ & $2(5)$ & 92 & 4.39 \\
\hline $5=$ & Symptom management? & $2(5)$ & 92 & 4.39 \\
\hline 6 & $\begin{array}{l}\text { Integrated approaches to delivery of care by respiratory nurses } \\
\text { with palliative care services }\end{array}$ & $4(16)$ & 87 & 4.35 \\
\hline 7 & Self-management and education related to bronchiectasis" & 2 (9) & 86 & 4.35 \\
\hline 8 & Smoking behaviours in teenagers and children and adults" & $1(1)$ & 81 & 4.31 \\
\hline 9 & The impact of training on the quality of spirometry & $3(14)$ & 88 & 4.32 \\
\hline 10 & The psychological management of anxiety and depression? & $2(4)$ & 88 & 4.28 \\
\hline
\end{tabular}

\#: Theme 1: Prevention of respiratory disease and related disability; Theme 2: Disease management; Theme 3: Organisation and delivery of care; Theme 4: Palliative care; see table 3 for topic numbering: ๆ: top ranked within own topic.

Theme 1: Prevention of respiratory disease and related disability

The top priority regarding smoking behaviours, particularly the use of e-cigarettes, reflects current interest in smoking cessation strategies. The evolution of e-cigarettes and the concern, particularly in children and adolescents, regarding uptake and the consequential nicotine addiction that may lead to future cigarette smoking is a topical issue [31]. The safety of e-cigarettes has not yet been definitively upheld and this remains a contentious area in the respiratory community [32]. It is possible that this current debate, and the ongoing acknowledgement that prevention of respiratory disease will primarily be achieved through reduction of smoking in the general population, has led to this definitive priority for research. Respiratory 
nurses could play a vital role in leading such research owing to their contact with these patient groups and nonspecialist healthcare professionals.

\section{Theme 2: Disease management}

Several practice areas were identified as future research priorities, including some disease-specific areas (e.g. patient understanding of asthma and self-management related to bronchiectasis). Most of these aspects of disease management would be regarded as essential to a respiratory nurse's practice and all relate to the patient education role that is often associated with, and performed, by respiratory nurses [5].

These priorities therefore reflect topical issues in the respiratory community that nurses can lead on and take forward as collaborative research projects. For example, asthma management features in the Asthma UK research strategy, which highlights that people need to understand, appreciate the benefits and comply with treatments [33]. Both psychological and lifestyle factors are highlighted in this strategy, emphasising the need to invest in research that enables and empowers people to take control of their condition so that they can live full and active lives. Additionally, the need for new studies to determine the effectiveness of self-management in bronchiectasis was prioritised by the EMBARC multistakeholder working group, a European Respiratory Society (ERS) Clinical Research Collaborative [13]. Clearly, nurses will play a central role in developing and researching such interventions.

\section{Theme 3: Organisation and delivery of care}

The priorities under "Organisation and delivery of care" are primarily concerned with establishing an evidence base of the impact of respiratory nursing on patient outcomes and experience, and the quality and benefits of specialist training for nurses; this is an area that has been underresearched to date. The literature appraising the effectiveness of the Respiratory Nurse Specialist is scant and systematic reviews are inconclusive [34]. Although there have been some trials of reasonable quality conducted demonstrating the efficacy of nurse-led care, these trials have been medically led, outcome measures were probably not sensitive to nursing input and the economic impact was not favourable to nursing [35]. The lack of research in this area has therefore potentially impacted on recent trends such as the dilution of specialist aspects of roles and, in some cases, downgrading experienced by respiratory nurses. Work has begun to examine the impact that respiratory nurses have on patient health outcomes and experiences, and the development of Respiratory Nurse Sensitive Outcome Indicators will be an important step towards evaluating fully the impact of respiratory nursing [36].

Evidence suggests that the quality of spirometry, particularly in primary care, is often substandard and that training is valuable in improving quality [37]; therefore, the need for a standardised approach towards education and training has already been identified [38]. The introduction of the ERS Spirometry Driving Licence has made some progress to setting an international standard for spirometry, and it will be incumbent on respiratory nurses and respiratory training organisations to ensure that the programme is rolled out and fully evaluated [3].

\section{Theme 4: Palliative care}

The issue of palliative care for respiratory patients and their carers has previously been neglected [39], but a focus on end-of-life care for respiratory patients has now highlighted palliative care needs [39, 40]. Respiratory nurses not only deliver but also often lead on palliative care services for respiratory patients [3], but despite end-of-life decision making being highlighted as a research priority for nurses in 1998 [9], there remains a dearth of evidence in relation to this area. Nurses can, and should, play an important role in taking forward this important programme of research.

\section{Strengths and limitations}

This study has several strengths due to its robust methodological approach, including the formulation of topics and items from the research recommendations in the literature, use of a clinical advisory group for discussion and development of the survey, the opportunity for respondents to nominate additional topics and items, and following of pre-determined criteria for inclusion and exclusion of items throughout the rounds. A broad recruitment approach allowed the survey to be as inclusive as possible and consistent responses throughout the later rounds demonstrated engagement from the targeted population. The demographics indicated a good spread across primary and secondary care, representing an experienced pool of nurses throughout the UK; it will be interesting to gain a European perspective in the future.

Limitations include the imprecise estimation of the response rate due to the organisational approach and unknown percentage of e-mails received and opened, rather than sent. The low numbers of paediatric nurses contributing to the survey was disappointing, although this was somewhat offset by those who indicated that they dealt with both paediatric and adult patients. It is worth noting that despite the 
importance within the survey, as evidenced by the large volume of comments made by respondents, Topics 3 ("Pulmonary rehabilitation"), 4 ("Psychological interventions") and 6 ("Family and unpaid carers") were not included in the top 10 ranked research priorities across all items in the survey. The contemporary nature of issues concerning organisation and delivery of care, particularly in relation to investment and value of the workforce, may have guided respondents to rank these delivery models above clinical issues. This may mirror some of the professional challenges facing nurse specialists today, e.g. defining the role/remit and cost-effectiveness of services. The survey identified respiratory nurse research priorities; further research with patients and carers could strengthen the empirical evidence for research priorities in respiratory nursing.

\section{Conclusions}

This Delphi study has successfully identified the key research priorities for respiratory nursing, by respiratory nurses, for the first time in the UK setting. The findings will serve to inform the ARNS research strategy, and will provide direction and priority for those wishing to undertake respiratory research. It will provide a focus for the support needed and produce opportunities for new collaborative research partnerships. Having a clear strategic direction, along with the appropriate support, research training and mentoring, is important for the future of the specialism; ultimately for empowering and providing opportunities for nurses to lead research that will enhance the respiratory care delivered to patients, their families and carers in the future.

Acknowledgements: We would like to thank ARNS members for their contribution to the survey. The team also wish to acknowledge the support and contribution of Dave Lynes (Innovation Lead, Edge Hill University, Ormskirk, UK) and members of the Respiratory Nurse Research Consortium in the development of the Delphi Survey; and Angela Hurlstone (ARNS Secretariat, Stoke Poges, UK) and the British Thoracic Society and Primary Care Research Society nursing groups for distributing the survey invitation to their members.

Conflict of interest: None declared.

Support statement: The ARNS funded this study. Funding information for this article has been deposited with the Crossref Funder Registry.

\section{References}

1 British Lung Foundation. The battle for breath: the impact of lung disease in the UK. 2016. https://cdn.shopify. com/s/files/1/0221/4446/files/The_Battle_for_Breath_report_48b7e0ee-dc5b-43a0-a25c-2593bf9516f4.pdf? 7045701451358472254 Date last accessed: December 22, 2017.

2 British Lung Foundation. Estimating the economic burden of respiratory illness in the UK. 2017. www.blf.org.uk/ what-we-do/our-research/economic-burden Date last accessed: August 8, 2017.

3 Loddenkemper R, Gibson GJ, Sibille Y, et al., eds. European Lung White Book. Sheffield, European Respiratory Society, 2015.

4 Fletcher MJ, Dahl BH. Expanding nurse practice in COPD: is it key to providing high quality, effective and safe patient care? Prim Care Respir J 2013; 22: 230-233.

5 Yorke J, Prigmore S, Hodson M, et al. Evaluation of the current landscape of respiratory nurse specialists in the UK: planning for the future needs of patients. BMJ Open Respir Res 2017; 4: e000210.

6 Taylor SJC, Candy B, Bryar RM, et al. Effectiveness of innovations in nurse led chronic disease management for patients with chronic obstructive pulmonary disease: systematic review of evidence. BMJ 2005; 331: 485 .

7 Dept of Health. NHS Five Year Forward View. 2014. www.england.nhs.uk/wp-content/uploads/2014/10/5yfv-web. pdf Date last accessed: September 23, 2016.

8 Sherrington R. We need to do research and shout about it - or fall behind. Nurs Times 2011; 107: 13.

9 Wewers ME, Brooks-Brunn JA, Hoffman L, et al. Research priorities in respiratory nursing. Am J Respir Crit Care Med 1998; 158: 2006-2015.

10 Larson JL, Ahijevych K, Gift A, et al. American Thoracic Society statement on research priorities in respiratory nursing. Am J Respir Crit Care Med 2006; 174: 471-478.

11 Moore S, Borthwick D, Darlison L, et al. Identifying research priorities for nurse specialists in lung cancer care. Cancer Nurs Pract 2007; 6: 23-28.

12 Bradley JM, Madge S, Morton AM, et al. Cystic fibrosis research in allied health and nursing professions. J Cyst Fibros 2012; 11: 387-392.

13 Aliberti S, Masefield S, Polverino E, et al. Research priorities in bronchiectasis: a consensus statement from the EMBARC Clinical Research Collaboration. Eur Respir J 2016; 48: 632-647.

14 Sheikh A. Developing consensus on national respiratory research priorities: key findings from the UK Respiratory Research Collaborative's e-Delphi exercise. Respir Med 2008; 102: 1089-1092.

15 Pinnock $\mathrm{H}, \varnothing$ strem A, Rodríguez MR, et al. Prioritising the respiratory research needs of primary care: the International Primary Care Respiratory Group (IPCRG) e-Delphi exercise. Prim Care Respir J 2012; 21: 19-27.

16 Malcolm C, Knighting K, Forbat L, et al. Prioritisation of future research topics for children's hospice care by its key stakeholders: a Delphi study. Palliat Med 2009; 23: 398-405.

17 Downing J, Knapp C, Muckaden MA, et al. Priorities for global research into children's palliative care: results of an International Delphi Study. BMC Palliat Care 2015; 14: 1-10.

18 Wiener B, Chacko S, Brown TR, et al. Delphi survey of research priorities. J Nurs Manag 2009; 17: 532-538.

19 Tume LN, Van den Hoogen A, Wielenga JM, et al. An electronic Delphi study to establish pediatric intensive care nursing research priorities in twenty European countries. Pediatr Crit Care Med 2014; 15: e206-e213. 
Jünger S, Payne S, Brine J, et al. Guidance on Conducting and REporting DElphi Studies (CREDES) in palliative care: recommendations based on a methodological systematic review. Palliat Med 2017; 31: 684-706.

McKenna H, Keeney S. Delphi studies. In: Watson R, Keady J, McKenna HP, eds. Researching Nursing Practice. London, Blackwell, 2008; pp. 251-261.

Williams PL, Webb C. The Delphi technique: a methodological discussion. J Adv Nurs 1994; 19: 180-186.

Hasson F, Keeney S, Mckenna H. Research guidelines for the Delphi survey technique. J Adv Nurs 2000; 32: $1008-1015$.

Keeney S, Hasson F, McKenna H. Consulting the oracle: ten lessons from using the Delphi technique in nursing research. J Adv Nurs 2006; 53: 205-212.

Von der Gracht H. Consensus measurement in Delphi studies. Technol Forecast Soc Change 2012; 79: 1525-1536.

Knighting K, O’Brien MR, Roe B, et al. Gaining consensus on family carer needs when caring for someone dying at home to develop the Carers' Alert Thermometer (CAT): a modified Delphi study. J Adv Nurs 2016; 72: 227-239.

Moher D, Liberati A, Tetzlaff J, et al. Preferred reporting items for systematic reviews and meta-analyses: the PRISMA statement. PLoS Med 2009; 6: e1000097.

Braun V, Clarke V. Using thematic analysis in psychology. Qual Res Psychol 2006; 3: 77-101.

Sawin K, Lewin LC, Niederhauser VP, et al. A survey of NAPNAP members' clinical and professional research priorities. J Paediatr Health Care 2012; 26: 5-15.

Cole ZD, Donohoe HM, Stellefson ML. Internet-based Delphi research: case based discussion. J Environ Manage 2013; 51: 511-523.

Bauld L, Angus K, de Andrade M. E-cigarette uptake and marketing! A report commissioned by Public Health England. 2014. www.gov.uk/government/uploads/system/uploads/attachment_data/file/311491/Ecigarette_uptake_ and_marketing.pdf Date last accessed: February 1, 2017.

2 Shapiro SD, Kaynar AM. Electronic cigarettes: the lesser of two evils, but how much less? Thorax 2016; 71: 1080-1081.

3 Asthma UK. Asthma UK's research priorities. 2016. www.asthma.org.uk/research/strategy/research-priorities Date last accessed: February 1, 2017.

4 Wong CX, Carson KV, Smith BJ. Home care by outreach nursing for chronic obstructive pulmonary disease. Cochrane Database Syst Rev 2012; 4: CD000994.

5 Sharples LD, Edmunds J, Bilton D, et al. A randomised controlled crossover trial of nurse practitioner versus doctor led outpatient care in a bronchiectasis clinic. Thorax 2002; 57: 661-666.

Prigmore S, Caress A, Yorke J. Development and preliminary psychometric testing of the Respiratory Nurse Sensitive Outcome Indicator tool (RNSOI) for patients with COPD. Eur Respir J 2017; 50: Suppl. 61, OA3234.

Eaton T, Withy S, Garrett JE, et al. The importance of quality assurance and the impact of spirometry workshops. Chest 1999; 116: 416-423.

8 Upton J, Madoc-Sutton H, Sheikh A, et al. National survey on the roles and training of primary care respiratory nurses in the UK in 2006: are we making progress? Prim Care Respir J 2007; 16: 284-290.

9 Lanken PN, Terry PB, De Lisser HM, et al. An Official American Thoracic Society Clinical Policy Statement: Palliative Care for Patients with Respiratory Diseases and Critical Illnesses. Am J Respir Crit Care Med 2007; 177: 912-927.

40 National Institute for Health and Clinical Excellence. Chronic obstructive pulmonary disease in over 16s: diagnosis and management. 2010. www.nice.org.uk/CG101 Date last accessed: January 14, 2017. 